\title{
Recurrent Variable Fetal Heart Rate Deceleration
}

National Cancer Institute

\section{Source}

National Cancer Institute. Recurrent Variable Fetal Heart Rate Deceleration. NCI

Thesaurus. Code C111778.

Variable decelerations that occur with greater than or equal to 50 percent of uterine contractions. They are usually associated with umbilical cord compression. 